\title{
I. The fusion constants of igneous rock.-Part I. The measurement of high temperature
}

\section{Carl Barus}

To cite this article: Carl Barus (1892) I. The fusion constants of igneous rock.-Part I. The measurement of high temperature, Philosophical Magazine Series 5, 34:206, 1-18, DOI: $10.1080 / 14786449208620160$

To link to this article: http://dx.doi.org/10.1080/14786449208620160

曲 Published online: 08 May 2009.

Submit your article to this journal $[\pi$

Џ Article views: 4

Q View related articles $\square$ 
LONDON, EDINBURGH, AND DUBLIN

\title{
PHILOSOPHICAL MAGAZINE
}

\author{
AND \\ JOURNAL OF SCIENCE.
}

\section{[FIFTH SERIES.]}

JUL $Y 1892$.

I. The Fusion Constants of Igneous Rock.-Part I. The Measurement of High Temperature. By CARL BaRUS*.

[Plate I.]

INTRODUCTORY.

1. $\boldsymbol{P} L A N$ of the Work.-The present paper opens a series of three researches made at the request of $\mathrm{Mr}$. Clarence King, for the purpose of elucidating certain fundamental questions in dynamic geology. The first paper is introductory, as stated above; the second $\dagger$ will investigate the amount and the character of the thermal contraction of a molten magma passing from liquid to solid; while the last paper $\ddagger$, in addition to furnishing data for the thermal capacity and the latent heat of fusion under the given conditions, has for its chief purpose the determination of the relation of melting-point to pressure. I will anticipate here sufficiently to state that not only is the rock-contraction specified thoroughly normal in type, but solidification occurs sharply at a definite temperature. Again, compatibly with the distinct value for the latent heat of fusion, the datum found for the pressure-coefficient of the melting-point of the silicate is of an order identical with the corresponding constant found for organic bodies, fusing normally.

* Communicated by the Author.

$\dagger$ See note in American Journal, December 1891.

$\ddagger$ See note in American Journal, January 1892.

Plil. Mag. S. 5. Vol. 34. No. 206. July 1892. 
2. Remarks on the present Paper.-The following hightemperature work was done nearly five years ago. Having the present occasion to corroborate the former results, I was gratified to find that in the lapse of time my original constants cannot have varied more than $4^{\circ}$ or $5^{\circ}$ at $1000^{\circ}$, while even this index of the time-error of the method can be largely explained away. It seems justifiable therefore to give the chief features of my method of work* a larger publicity than it will reach in a geological bulletin.

Apart from this, since M. H. Le Chateliert has thrown discredit on the platinum-iridioplatinum thermocouple, it becomes incumbent on me to endeavour to restore the prestige of the older couple, lest the same slur should also come over my work. Let me remark in passing, that though I have no doubt of the trustworthiness of the platinum-rhodium couple, nobody has as yet taken the pains to put it to the severe test of a direct air-thermometer comparison, through which I have put the platinum-iridium couple. I have long hoped to find the time to do this myself.

The present paper, therefore, though its main object is a study of the thermoelectric or thermal behaviour of the platinum-iridium couple, enters somewhat minutely into hightemperature air-thermometry in general.

3. Literature. A consideration of the earlier work, for which there is no room here, will be found in the Bulletin cited, pp. 23-55.

\section{Apparatus For AIR-Thermometry.}

4. Preliminary Remark as to Methods.-Constant-volume air-thermometry is scarcely suitable for high temperature work, for it is not safe to bring pressure to bear on the whitehot porcelain bulb. This objection applies in a measure to Deville and Troost's Sprengel-pump method, which has an additional incovenience in not being continuous, so that the fiducial volume is lost. On the other hand, the constantpressure method is free from these objections, and my best comparisons were obtained by means of it. Such an airthermometer, as I shall endeavour to show, is complete in itself, admitting of a redetermination of the fiducial constants (volume of bulb, coefficient of expansion, fiducial zero) without taking the instrument apart $(\$ \S 13,14)$.

* Cf. Annual Report of the Director U. S. G. S., 1881-82, p. 9; ibid. $1883-84$, p. 62 ; ibid. 1886-87, p. 192. The full account is to be found in Bulletin U.S. Geological Survey, No. liv. pp. 56 to 238 (1889).

$\dagger$ C. R. cii. p. 819 (1886); Bull. Soc. Chim. xlv. p. 482 (1886). 
5. Porcelain Bulbs.-The forms of air-thermometer bulbs of porcelain which $I$ used are shown on a scale of $\frac{1}{4} \mathrm{in}$. (figs. 1, 2,3). They were made by Morlent frères, Paris, of the very refractory porcelain of Bayeux. Fig. 1 is the earliest form. Bulb and stem are in one piece, and put together by the maker before firing. In consequence of the

Fig. 1.-Non-inglazed, non-reentrant porcelain air-thermometer bulb. Scale 1/4.

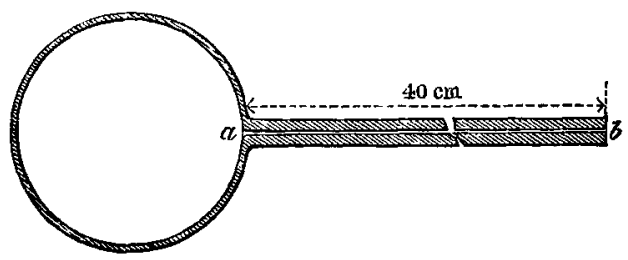

long capillary stem $(0.1$ centim. in bore), it is all but impossible to glaze these bulbs internally, and this is not attempted. Their capacity is somewhat over 300 cub. centim., and the mean thickness of the porcelain walls about $0 \cdot 27$ centim. The stem, which is, say, 40 centim. long, has a volume of about $0.012 \mathrm{cub}$. centim. per centimetre.

To use such a bulb for calibrating a thermocouple, it would be necessary to have a space at an almost unattainably constant high temperature : for the couple is practically a point, and its thermal sensitiveness is instantaneous, whereas the large bulb necessarily lags behind changes of temperature. With the object of eliminating this source of serious error, I had the bulbs made in the shape of fig. 2, the bottom of which is reentrant, projecting inward to form an axial tube, $m n$,

Fig. 2.-Non-inglazed reentrant porcelain air-thermometer bulb. Scale 1/4.

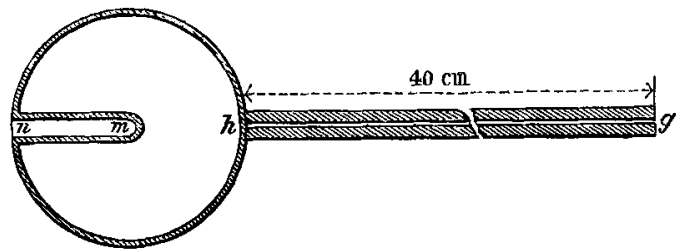

closed at the centre of figure, $m$. Into this tube the end of the properly insulated thermocouple is introduced, with its junction at $m$. The insulator, $\$ 10$, incidentally subserves the purpose of a plug for the open end of the tube $m n$, 
whereby radiation here is made imperceptible. In this reentrant pattern symmetry of form has been sacrificed in order to secure greater identity in the exposure of the air-thermometer and the thermocouple. Deville and Troust condemn the non-spherical bulb, but I have not in my experiments with the reentrant form found any evidence to agree with them. At all events the expansion error is much less serious than the calibration error in question $(\$ 14)$.

The amount of gas or moisture forcibly retained by the pores of the non-inglazed porcelain bulb may be greater than the manometer pressure indicates. There is apparent difficulty, moreover, in defining the interval volume, a quantity which in constant-pressure air-thermometry enters essentially into the formulæ for computing temperature. Hence Deville and Troost devized bulbs which could be glazed both within and without, as shown in fig. 3 . Here the bulb $c d p$ and the stem of are distinct parts. They are calibrated separately, and

Fig. 3.--Inglazed non-reentrant porcelain air-thermometer bulb and stem. Scale 1/4.

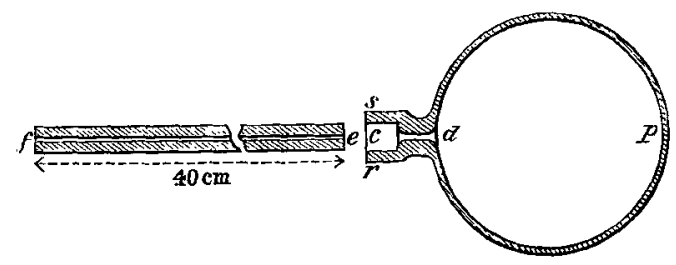

prior to using are soldered together with felspar and the oxyhydrogen blowpipe. The bulb, $c d p$, ends in a short neck, $c d r s$, just large enough to receive the stem, ef, snugly, and the canal, $c d$, through which the bulb is glazed, eventually becomes the prolongation of the capillary canal of the stem.

Bulbs combining the features of figs. 2 and 3 , being both reentrant and inglazed, were not in hand at the time.

Porcelain soldering is difficult, and calls for skill and patience. I found that after fastening the bulb to a rapidly rotating whirling-table, with the stem-axis vertical and coinciding with the axis of rotation, the operation was much facilitated. Symmetrical heating greatly diminishes the danger of breakage to which the bulb is liable because of the intense heat of the impinging flame. The machine is described in the Bulletin. Cf. $\$ 18$.

At best, however, vacuum-proof joints are sparingly obtained, say one in every five solderings, and samples neat in external appearance are frequently worthless. If, therefore, 
in the following pages I have proved that bulbs not glazed internally are quite available for the exact air-thermometry of high temperatures, one of the serious difficulties which the work entails will have been removed.

6. Metallic Capillary Tubes*.-The bulb and the manometer are joined by seamless metallic capillary tubes, about 200 centim. or more long, and $\cdot 05$ centim. in diameter within. These tubes are to be cut apart near the middle, and joined by a suitable three-way glass stopcock, through which the bulb may be exhausted and thoroughly dried at red heat, and both bulb and manometer finally charged with the necessary amount of dry air or other gas.

Capillary tubes may be made of either copper, silver, or platinum. The latter are preferable because they do not amalgamate in case of an accidental contact with mercury. I succeeded in making copper capillaries myself, by filling a thick copper tube with fusible metal, rolling and drawing the tube down to a wire, and finally melting out the fusible core under slight pressure applied at one end of the tube. Tubes of the kind necessary, however, are now in the market, and may be obtained in lengths not exceeding 5 metres. As employed in the work below, an external diameter of 11 centim. to a bore of $\cdot 056$ centim., or a volume of $\cdot 0025$ cub. centim. per centimetre of length, was found to insure a sufficiently rapid flow of gas from bulb to manometer, while the air contained in the capillary is nearly negligible in amount.

7. Manometer.-This is practically a U-tube, one branch of which is made of glass, 150 centim. long, ascurately graduated in cubic centimetres, with a total capacity of about 300 cub. centim. Into the top of this tube, the available end of the platinum capillary, tapering to a fine conical point, is suitably soldered with cement. The point so adjusted is a convenient fiducial mark, the registration being made either by optical or by electric contact with the mercury meniscus of the manometer. The other branch of the U-tube is flexible, and communicates with a sufficiently large mercury cistern, which may be raised or lowered at pleasure. The whole is attached to a prismatic stand, 2 metres high, consisting of four uprights rigidly joined at the top and the bottom. Observations are made for equal heights of the mercury in both branches, by the cathetometer. A barometer is attached to the stand. Sensitive thermometers at the lower and the upper end of the glass measuring-tube 'show its temperature. $C t . \S 18$.

* First used by Regnault (Relation des Expériences, Paris, 1847, p. 264). 
8. Revolving Muffle.-In order that corresponding indications of thermocouple and air-thermometer may be compared, both must be placed in a space at practically uniform temperature, which must be variable at pleasure from ordinary temperatures to extreme white heat. I constructed a special furnace for this purpose, in the way indicated in plan in the diagram (fig. 4). The body of the furnace is a thick cylindrical box, B B, surmounted by a hemispherical lid, suitably

Fig. 4.-Plan of the revolving muffe, Diagram.

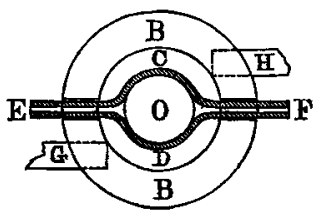

perforated. In this cylindrical enclosure a spherical muffle, C D, provided with hollow lateral arms or axles, $\mathbf{E} \mathbf{F}$, and placed symmetrically with respect to the centre of figure, is free to rotate around the horizontal axis of the arms. If the rate of rotation be sufficient, this insures constancy of temperature within the muffle around the horizontal EF. Two blastburners, $G$ and $H$, purposely placed tangentially so as to be equivalent to a force-couple, blow a vortex of flame into this furnace, equalizing temperature around the vertical. Virtually, therefore, the muffle, regarded as a geometrical sphere, has two rotations, one round $E F$, and the other round the vertical through $\mathrm{O}$. To make this apparatus theoretically perfect a third rotation, round a horizontal axis through $O$, and perpendicular to EF, would have to be supplied. This third rotation is a mechanical impossibility, bearing always in mind that cumbersome or complicated apparatus would rather detract from the end to be obtained than add to it.

In the spherical space of constant temperature thus obtained is placed the bulb of the air-thermometer (not shown), with its stem projecting into or through the axle $\mathrm{F}$; and the bulb is held in position, free from the muffle, by a clamp attached to the stem on the outside of the furnace. The thermocouple is introduced through the opposite $\operatorname{arm~} \mathrm{E}$, and its junction lies at the centre of figure of the bulb (fig. 2, above). It is an essential part of the construction of the furnace that during rotation the muffle touches neither the air-thermometer nor the insulator of the thermocouple, the latter being also supported by a clamp on the outside of the furnace.

The practical for $m$ of this furnace, which after many trials 


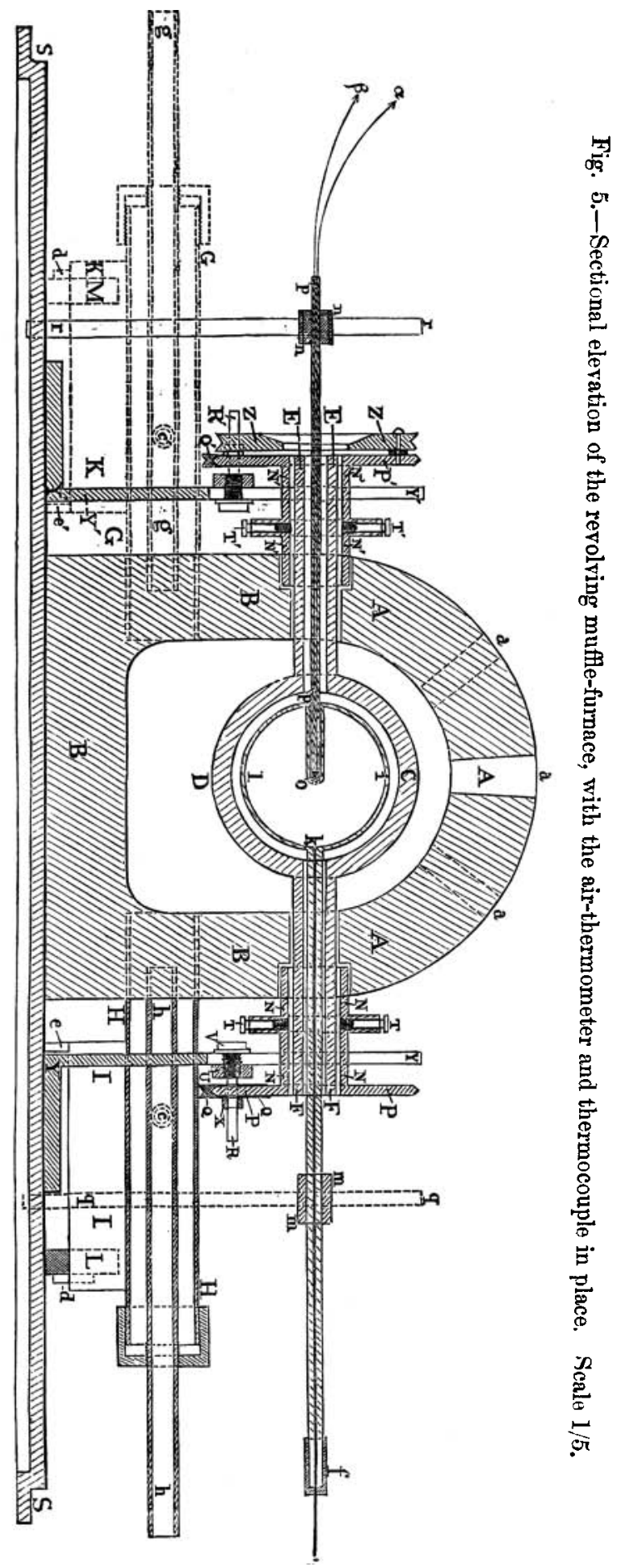


was found satisfactory, is shown in longitudinal section (scale $\frac{1}{5}$ ) in fig. 5, where B B B is the cylindrical body, and A A A the dome-shaped lid (perforated at $a a a$ ) already referred to. The burners $H H$ and $G G$, project into the furnace as far as the inner surface, and their construction is shown. Compressed air enters the tubes $g g$ and $h h$, and the gas inlets are at $c$ and $c^{\prime}$. Attached to the burners are the rectangular slides II and $K K$, which pass through guides $\mathrm{L}$ and $\mathrm{M}$. The pins $e e$ and $d d$ further regulate the action, by which the burners can be easily inserted in or withdrawn from the furnace. Finally, the gas inlets, $c$ and $c^{\prime}$, are each in connexion with a graduated stopcock (half-inch clear bore), by which the gas-supply, and hence the furnace temperature, can be regulated at pleasure. In this way the torch of flame, fully two feet in length, is reduced to a blue cone about eight inches long by the blast, which may then be further reduced to a mere ribbon of flame by shutting off the gascocks. Burner explosions do not occur.

The muffle proper is shown at E C F E in fig. 5, and consists of two identical halves of refractory fire-clay, each of which is a hemisphere with two diametrically opposite guttered arms; the two halves are placed together with their flat faces contiguous, but without cement, and secured by surrounding the axles with appropriate collars of iron, $\mathrm{N} \mathrm{N}$ and $\mathrm{N}^{\prime} \mathrm{N}^{\prime}$ (fig. 5), the outer edges of which are widely flanged. These flanges, $\mathrm{E} P$ and $\mathrm{P}^{\prime} \mathrm{P}^{\prime}$, are turned circularly with their circumferences bevelled so as to fit the grooves of two pairs of friction-rollers, $Q Q$ and $Q^{\prime} Q^{\prime}$, of which $R$ and $R^{\prime}$ are the respective axes, four in number. Set screws, $T, T^{\prime}$, sink into the rib of the collar and fasten it to the axle, asbestos being usually interposed.

The four friction-rollers, $Q Q^{\prime}$, are adjustable (see figure), so that the muffle in its rotation never touches the walls of the furnace, but revolves on the rollers. Such an arrangement is essential, for the rolling parts must be placed at some distance from the hot parts of the axle to slide smoothly; and the friction of an imperfect mechanism would, at high temperatures, tend to wrench off the axles of the white-hot muffle. Another essential adjustment may here be mentioned. After firing, neither do the axles of the muffle coincide in prolongation nor are they straight. Hence the friction rollers, $Q Q^{\prime}$, rotate on cylindrical rods, $R R^{\prime}$, along which the former are in some measure free to slide, their extreme positions being fixed by four adjustable collars, $\mathbf{X} \mathbf{X}^{\prime}$.

The belt pully, Z Z $Z^{\prime}$, supplies the power.

Finally, the figure shows the air-thermometer $f k i l$ in 
position, supported by the universal clamp $m m$, attached to the vertical rod $q q$. A similar clamp $n n$, on the opposite side of the furnace, supports the insulator of the thermoconple $p p$. The ends of the wires of the latter appear at $a$ and $\beta$, and pass thence to a petroleum bath at known temperature, where they are suitably connected with the terminals of the measuring apparatus (insulated mercury cups submerged in the petroleum).

The figure-shows that the thermocouples to be calibrated may be easily inserted or withdrawn while the air-thermometer remains in place. I will pass over the method of adjusting the latter, remarking only that the collar $\mathrm{P}$ has a slit cut through it, from end to end, in the direction of a radial plane, and sufficiently wide to admit the platinum capillary $s$ of the air-thermometer. This need not, therefore, be taken apart to remove it from the muffle.

9. Remarks on the Furnace.-The maximum temperature attainable is indefinitely high, much higher than can be measured by the porcelain air-thermometer. Measurements may be made either while temperature is slowly increasing or decreasing ; in the latter case the gas may be quite shut off below $500^{\circ}$, for the furnace itself then cools sufficiently slowly. My mean rate of rotation was about 50 per minute, but smaller rates are necessary at very high temperatures when the muffle begins to become viscous, and at low temperatures. During the heating to white heat, the parts of the axles within the furnace are liable to be hotter than the muffle. I will omit the method of remedying this defect, since it is quite absent on cooling, and since its effective value is almost negligible. Its harmful tendency is chiefly to bend the stem of the air-thermometer, an effect which can be counteracted by rotating the latter $180^{\circ}$ from time to time. Rotation, moreover, keeps the muffle straight even when the clay is approaching the viscous stage.

Protected from direct flame by the revolving muffle, the fragile porcelain bulbs are heated with great regularity, and the liability of the thermometer to break is therefore nil. The furnace has been so made that the zone of variable temperature which surrounds the stem of the thermometer is as narrow as possible. Indeed the correction is almost superfluous. Were it desirable to use a compensator (a duplicate porcelain stem, closed at the bulb end, to gauge the stem error), this instrument may either temporarily replace the thermocouple, or be introduced through an independent lateral tube, corresponding to the axles $\mathrm{F} F$.

In order to obtain the zero or fixed point of the bulb, the 
latter is taken out of the muffle and submerged in water of known temperature; but check-readings may be obtained when the (cold) bulb is in place in the furnace, by inserting the reservoir of a sensitive mercury thermometer into the tube of the reentrant bulb, fig. 2.

A special advantage of the furnace (which should always be heavily jacketed with asbestos and banded with iron) is the fact that the observer can get very near it without inconvenience. Rotating parts may be lubricated. An elliptic

Fig. 6.-Plan of the elliptic revolving muffle, with the airthermometers in place. Diagram.

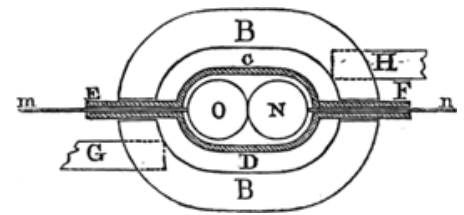

revolving muffle for the comparison of two gas-thermometers has also suggested itself, particularly in view of the fact that since the stem errors in this case vanish, comparisons may be made with great ancuracy. This is shown in figure 6 , where E C D F is the muffle and $\mathrm{O} m$ and $\mathrm{N} n$ the two gas thermometers to be compared.

\section{Thermoelectric Apparates.}

10. Wires and Insulators.-The thermocouples used consisted of platinum combined with an alloy of platinum and 20 per cent. of iridium. The wires were cut in lengths of a metre each, from large coils, and successive lengths showed the same electric properties. Even when melted down on lime hearths before the oxyhydrogen blowpipe and drawn over again, the constants of the couples were not found to have appreciably ( $\frac{1}{10}$ per cent.) changed. The wires should be annealed at red heat before using.

In order to keep the wires apart, I devised a machine by which doubly perforated insulators could be pressed, much in the manner of lead-pipe manufacture. The insulators were made of very refractory fire-clay, 25 or 30 centim. long, and $\cdot 5$ or $\cdot 6$ centim. thick, with two parallel canals, each $\cdot 1$ centim. in diameter, running from end to end.

11. Zero Method.-All my thermoelectric effects are measured, as electromotive force, in terms of a given Latimer Clark's standard cell. The connexions made are easily 
understood from figure 7, where $R$ and $R^{\prime}$ are rheostats, having about 35,000 ohms available, and $r$ is a bridge-rheostat containing a duplicate scale of 10 , as bigh as 10,000 . The cold

Fig. 7.-Zero method of thermoelectric measurement. Diagram.

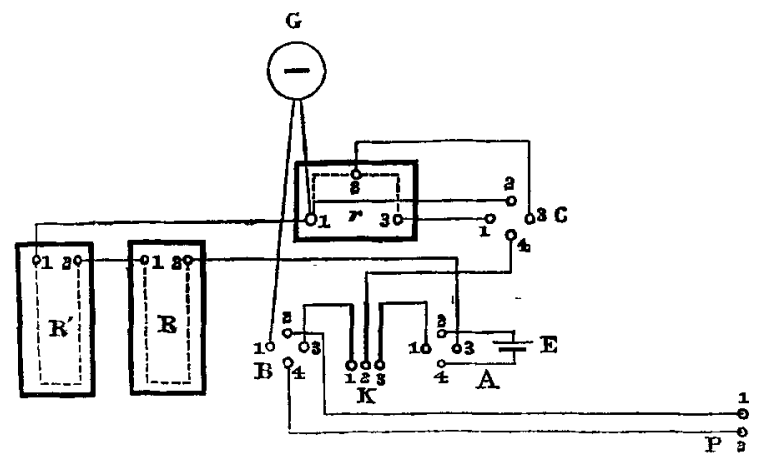

ends of the thermocouple communicate with the terminals at $\mathrm{P}$, under petroleum. Two zinc-sulphate Daniells are inserted at $\mathrm{E}$. The commutators $\mathrm{A}$ and $\mathrm{B}$ are useful in measuring small electromotive forces, since by simultaneously reversing both of them, all disturbing thermo-currents in the connexions are eliminated from the mean result. $K$ is a duplex key constructed as shown in figure 8 , where two of the mercury cups (conveying the battery current from $\mathrm{E})$ are filled to a higher level than the third. By aid of the keys at $O$ the resistances $r$ can be inserted either in parallel or in series. $G$ is a sensitive Thomson galvanometer.

Fig. 8.--Form of double key. Diagram.

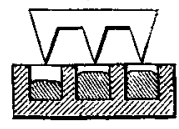

The thermoelectric forces are directly expressed in terms of $\mathrm{E}$, which is compared from time to time with the given standard Clark cell, the poles of which are temporarily put in connexion with $P$. The reduction of observations is facilitated by suitable tables, computed once for all.

In this way my thermoelectric data have the same high degree of constancy in the lapse of time (years) as the standard cell in question. I have found this method, though it is somewhat more laborious, much more trustworthy than the torsion-galvanometer, with which I have also worked*. Even when the conditions are so chosen that the thermoelectric forces are expressed solely in terms of the torsion of the suspending fibre, it is not to be forgotten that increase of

* See this Magazine, xxix. p. 146 (1890). 
the room temperature both decreases the effective magnetic field and increases the resistance of the coil, by a combined amount probably greater than 0.4 per cent. per degree. Hence in a room of variable temperature (the usual case), the torsion-galvanometer of unknown temperature-coefficient is liable to lead to serious errors.

\section{RESULTS.}

12. Method of Computation.-I will pass over this here, for the forms to be given to the cumbersome equations depend upon the special purpose of the observer. Suffice it to say that I divided the total gas volume into 4 parts, viz., the volume of the bulb and hot stem, the volume of the part of the stem where temperature falls off from hot to cold, the volume of the cold stem and capillary, and finally the volume measured in the manometer. The effect of each of these parts on the final result was carefully evaluated.

13. Bulb Volumetry.-The volume of the bulb at zero Centigrade, which enters fundamentally into the constantpressure method, can be obtained by water calibration, $c f$. $\$ 18$. In the case of a manometer like the one described above, $\S 7$, in which pressure can be varied over a sufficiently wide range and volumes read off with facility, the bulbvolume may also be obtained by air volumetry. For instance, if $v$ and $p$ be corresponding values for the volume of air in the manometer and the pressure, the following values were obtained for the bulb volume, $v_{0}$ :-

$$
\begin{aligned}
& p=75 \cdot 24,52 \cdot 64 ; \quad 75 \cdot 22,53 \cdot 41 ; \quad 75 \cdot 54,53 \cdot 38 ; \quad 53 \cdot 38,75 \cdot 53
\end{aligned}
$$

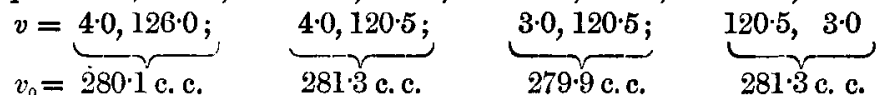

After much further experimentation I convinced myself that the differences here are simply thermal discrepancies, and are not due to the non-glazed interior surface of the bulb. If the high-temperature datum is to be measured with an absolute accuracy of $1^{\circ}$ in $1000^{\circ}$, the $v_{0}$ must be known with a degree of precision scarcely exceeding .02 per cent., i. e. to about $0.1 \mathrm{c}$. c. in the above case. Supposing sufficiently sharp means (accurate to $0^{\circ} 05$ C.) for measuring or controlling temperature to be at hand (the above data were made with the manometer in air), the stated accuracy is attainable.

14. Coefficient of Expansion of Porcelain.-The porcelain of Bayeux, in addition to its refractory qualities, has an 
advantage inasmuch as the (small) coefficient of thermal expansion is known *. The bulbs are supposed to have been so thoroughly fired at the outset that all permanent volume changes have vanished. It is clear, however, that by using the above manometer in case of the constant-pressure method, the coefficient of expansion of the bulb may also be measured by air volumetry. Let the manometer volume be changed while the (high) temperature of the bulb is nearly constant by varying the manometer pressure. Then, if $\mathrm{H}_{1}, \mathrm{~V}_{1}, \mathrm{~T}_{1}$, and $\mathrm{H}_{2}, \mathrm{~V}_{2}, \mathrm{~T}_{2}$, be two successive readings of the pressure, volume, and temperature, respectively, at the manometer, and if $f(\mathrm{~T})=(1+\beta \mathrm{T}) /\left(1+a^{\prime} \mathrm{T}\right)$, where $\beta$ is the coefficient of expansion of porcelain, and $a$ that of air, it follows that

$$
f^{\prime}(\mathrm{T})+\Sigma\left(\frac{v}{v} f\left(\mathrm{~T}^{\prime}\right)\right)=\frac{\frac{\mathrm{H}_{2} \mathrm{~V}_{2}}{v} f\left(\mathrm{~T}_{2}\right)-\frac{\mathrm{H}_{1} \mathrm{~V}_{1}}{v} f\left(\mathrm{~T}_{1}\right)}{\mathrm{H}_{1}-\mathrm{H}_{2}}, .
$$

where $\mathrm{T}$ is the (hign) temperature and $v$ the zero volume of the bulb, and where $\mathrm{\Sigma}$ contains the corrective members (stem volumes and temperatures). If $\mathrm{H}_{2}$ be the barometric height for the day, $\mathrm{T}$ can be at once computed by the ordinary formula, and $\beta$ may then be computed from $f(T)$ in (1). In the following table the measurements for $T$ alternate with the measurement for $\beta$ in time series, so that corresponding values are given.

Table I.-Thermal Expansion of Porcelain.

\begin{tabular}{|c|c|c|c|c|c|}
\hline Time. & T. & $\beta \times 10^{6}$. & Time. & T. & $\beta \times 10^{6}$. \\
\hline$m$ & & & m & & \\
5 & 568 & & 9 & 978 & \\
8 & $(564)$ & 22 & 16 & $(993)$ & 37 \\
18 & 560 & & 24 & 1002 & \\
21 & $(564)$ & 26 & 26 & $(1004)$ & 27 \\
40 & 567 & & 32 & 1006 & \\
\hline
\end{tabular}

In view of the fact that the quantities on which $\beta$ ultimately depends are of the same order of magnitude as the stem error $\Sigma$ (of which more presently, $\S \S 17,18$ ), this method cannot

* Deville and Troost, C. R. lix. p. 162 (1864). 
yet be looked to for close results. The data, crude as they are, however, show that $\beta$ is determinable by this method with the same degree of accuracy with which it is to be applied, or that the stem error and $\beta$ are determinable in terms of each other reciprocally. In this respect the constantpressure method of high-temperature air-thermometry is unique, since it admits of easy modifications, by which the zero volume of the bulb, its coefficient of expansion, as well as all permanent changes of volume, may be evaluated without extra appliances.

15. Tables.-In making extensive comparisons between the thermocouple and the air-thermometer, I had three objects chiefly in view :-(1) To find out whether the temperature indications of the platinum-iridium thermocouple were regular and free from serious anomalies, in other words to calibrate the couple; (2) To compare the indications of different non-inglazed porcelain bulbs, for which purpose I compared two bulbs (Nos. 1 and 2) with the same thermocouple under identical conditions; (3) To find whether the flow of air between bulb and manometer was seriously retarded by the interposed lengths of metallic capillary tubes. This was discernible by comparing the data obtained when the furnace temperature gradually increased, with the data for decreasing furnace temperature (cooling).

Accordingly, I have two sets of results in hand, the first obtained with bulb No. 1, and consisting of four series of data obtained on different days ; the second set obtained with bulb No. 2, and consisting of five series of results. Of these I will only reproduce the latter (Bulb 2) here, inasmuch as these data are in many respects the more accurate. Corrections for the permanent volume-contraction of the bulb obtained from volumetric measurements made before and after each series of heatings are applied.

In Tables II., III., and IV., "No." refers to the thermocouple used, $e_{20}$ is the thermoelectromotive force when the cold junction is at $20^{\circ} \mathrm{C}$. and the hot junction at the airthermometer temperature $\mathrm{T}$. 
TABLE Il.-Calibration of Platinum-Iridium Thermocouples.

\begin{tabular}{|c|c|c|c|c|c|c|c|c|}
\hline \multicolumn{9}{|c|}{ Series I. } \\
\hline No. & $e_{20}$ & T. & No. & $e_{20}$ & T. & No. & $e_{20}$ & T. \\
\hline $\begin{array}{l}37 \\
37 \\
37 \\
37 \\
39 \\
39 \\
39 \\
39 \\
39 \\
37 \\
37 \\
37\end{array}$ & $\begin{array}{c}\text { microvolt. } \\
3440 \\
3570 \\
3700 \\
3770 \\
3850 \\
3900 \\
7970 \\
8340 \\
8470 \\
8670 \\
8800 \\
8800\end{array}$ & $\begin{array}{l}{ }^{\circ} \mathrm{C} . \\
359 \\
373 \\
379 \\
385 \\
393 \\
396 \\
703 \\
733 \\
744 \\
758 \\
762 \\
763\end{array}$ & $\begin{array}{l}37 \\
37 \\
37 \\
39 \\
39 \\
39 \\
39 \\
39 \\
39 \\
37 \\
37 \\
37\end{array}$ & $\begin{array}{c}\text { microvolt. } \\
10640 \\
10850 \\
11080 \\
11090 \\
11070 \\
11050 \\
12120 \\
12290 \\
12440 \\
11720 \\
11470 \\
11400\end{array}$ & $\begin{array}{r}\circ \mathrm{O} . \\
895 \\
910 \\
928 \\
938 \\
931 \\
927 \\
972 \\
991 \\
1019 \\
963 \\
949 \\
952\end{array}$ & $\begin{array}{l}37 \\
37 \\
37 \\
37 \\
37 \\
37 \\
37 \\
37 \\
37 \\
37 \\
37 \\
37 \\
37 \\
37\end{array}$ & $\begin{array}{c}\text { microvolt. } \\
\ldots \ldots \ldots . . \\
8900 \\
8160 \\
7450 \\
6580 \\
6080 \\
5590 \\
5060 \\
4730 \\
4330 \\
3940 \\
3660 \\
3370 \\
\ldots \ldots \ldots .\end{array}$ & $\begin{array}{l}{ }^{\circ} \mathrm{C} . \\
842 \\
779 \\
724 \\
665 \\
606 \\
567 \\
529 \\
493 \\
460 \\
430 \\
402 \\
375 \\
351 \\
330\end{array}$ \\
\hline
\end{tabular}

Table III.-Calibration of Platinum-Iridium Thermocouples.

\begin{tabular}{|c|c|c|c|c|c|c|c|c|}
\hline \multicolumn{3}{|c|}{ Serins II. } & \multicolumn{3}{|c|}{ SERIEs III. } & \multicolumn{3}{|c|}{ Series IV. } \\
\hline No. & $e_{20}$ & T. & No. & $e_{20}$ & T. & No. & $e_{20}$ & 'T. \\
\hline $\begin{array}{l}37 \\
37 \\
37 \\
37 \\
37 \\
37 \\
37 \\
37 \\
37 \\
37 \\
37 \\
37 \\
37 \\
37 \\
37\end{array}$ & $\begin{array}{c}\text { microvolt. } \\
12650 \\
12870 \\
13250 \\
13360 \\
11250 \\
10150 \\
9170 \\
8240 \\
7540 \\
6780 \\
6250 \\
5660 \\
5220 \\
4820 \\
\ldots \ldots \ldots . .\end{array}$ & $\begin{array}{r}{ }^{\circ} \mathrm{C} . \\
1030 \\
1048 \\
1075 \\
1080 \\
934 \\
858 \\
789 \\
726 \\
671 \\
618 \\
575 \\
534 \\
499 \\
462 \\
433\end{array}$ & $\begin{array}{l}39 \\
39 \\
39 \\
39 \\
39 \\
39 \\
39 \\
39 \\
39 \\
39 \\
39 \\
39 \\
39 \\
39 \\
39 \\
39 \\
39 \\
39\end{array}$ & $\begin{array}{c}\text { microvolt. } \\
11900 \\
12370 \\
12590 \\
12850 \\
12910 \\
11570 \\
11080 \\
9880 \\
8880 \\
8180 \\
7350 \\
6780 \\
6170 \\
5550 \\
5150 \\
4700 \\
4350 \\
\ldots \ldots \ldots . .\end{array}$ & $\begin{array}{r}{ }^{\circ} \mathrm{C} . \\
989 \\
1019 \\
1028 \\
1051 \\
1054 \\
965 \\
929 \\
846 \\
778 \\
721 \\
664 \\
616 \\
573 \\
527 \\
494 \\
458 \\
426 \\
403\end{array}$ & $\begin{array}{l}37 \\
37 \\
37 \\
37 \\
37 \\
37 \\
37 \\
37 \\
37 \\
37 \\
37 \\
37 \\
37 \\
37 \\
37 \\
37\end{array}$ & $\begin{array}{c}\text { microvolt. } \\
12040 \\
12060 \\
12110 \\
12140 \\
11120 \\
10040 \\
8970 \\
8110 \\
7410 \\
6740 \\
6180 \\
5640 \\
5140 \\
4740 \\
4350 \\
4140\end{array}$ & $\begin{array}{l}{ }^{\circ} \mathrm{C} . \\
985 \\
990 \\
990 \\
995 \\
923 \\
847 \\
773 \\
714 \\
659 \\
609 \\
569 \\
531 \\
490 \\
459 \\
427 \\
413\end{array}$ \\
\hline
\end{tabular}


TABLE IV.-Calibration of Platinum-Iridium Thermocouples.

\begin{tabular}{|c|c|c|c|c|c|c|c|c|}
\hline \multicolumn{9}{|c|}{ SHRIES V. } \\
\hline No. & $e_{20}$ & T. & No. & $e_{20}$ & T. & No. & $e_{20}$ & T. \\
\hline $\begin{array}{l}38 \\
38 \\
38 \\
38 \\
38 \\
38 \\
38 \\
38 \\
38\end{array}$ & $\begin{array}{c}\text { microvolt. } \\
5370 \\
5560 \\
5900 \\
5930 \\
6030 \\
6100 \\
8340 \\
8500 \\
8850\end{array}$ & $\begin{array}{l}{ }^{\circ} \mathrm{C} . \\
512 \\
526 \\
565 \\
568 \\
560 \\
567 \\
734 \\
742 \\
760\end{array}$ & $\begin{array}{l}38 \\
38 \\
38 \\
38 \\
38 \\
38 \\
38 \\
38 \\
38\end{array}$ & $\begin{array}{c}\text { microvolt. } \\
9030 \\
11700 \\
11950 \\
12300 \\
12430 \\
11470 \\
10130 \\
9190 \\
8270\end{array}$ & $\begin{array}{r}\circ \mathrm{O} . \\
774 \\
958 \\
978 \\
1002 \\
1006 \\
935 \\
852 \\
790 \\
722\end{array}$ & $\begin{array}{l}38 \\
38 \\
38 \\
38 \\
38 \\
38 \\
38 \\
\mathbf{3 8}\end{array}$ & $\begin{array}{c}\text { microvolt. } \\
7580 \\
6860 \\
6300 \\
\mathbf{5 7 4 0} \\
5290 \\
4880 \\
4450 \\
4100\end{array}$ & $\begin{array}{l}\circ 0 . \\
671 \\
622 \\
579 \\
539 \\
501 \\
467 \\
435 \\
405\end{array}$ \\
\hline
\end{tabular}

16. Chart.-The results of these three tables are represented graphically by making $e_{20}$ a function of $\mathrm{T}$ in Pl. I., which may be said to be the final result of the calibration problem in hand. Caudal dashes, which point upward and to the right when the furnace temperature is increasing, and downward or to the left when it is decreasing, distinguish the different series of points. It is to be remembered that into this chart are crowded all the accidental errors and observational errors of air-thermometer and thermoelectric measurement, when the whole work is done by a single observer. If the curve, Pl. I., be linearly prolonged above $1200^{\circ}$, then the junction of the couple eventually fuses at $1800^{\circ}$, as I find by experiment.

\section{Discussion.}

17. Errors of Measurement.-To interpret the chart, Pl. I., it is necessary to enter minutely into a consideration of the observational errors which affect the result $1^{\circ}$ in $1000^{\circ}$. The divers quantities which enter saliently into the equation for constant-pressure air-thermometry are-

$$
t, \mathrm{~T}_{1}, \nabla_{1} / v, v^{\prime} / v, \mathrm{H} / h, \alpha, \beta,
$$

where $t$ is the fiducial temperature and $v$ the volume of the bulb, $h$ the fiducial tension of the gas; where at the high temperature, $V_{1}, T_{1}, H$ are the volume, temperature, and tension of the gas in the manometer; and where finally $v^{\prime}, \alpha, \beta$ are the stem volume and the coefficients of expansion of gas and of porcelain respectively. I have done this both for the 
above ratios and for the individual quantities, but the results cannot be reproduced here. After a minute and careful comparison of all of this (see Bulletin, No. 54, pp. 227-233), I concluded that the values of high temperature obtained in case of the two reentrant bulbs, Nos. 1 and 2, not glazed internally, were identical ; that by using the revolving mufflefurnace described above $(\$ 8)$ temperature (increasing or decreasing) changes slowly enough to permit the use of the above metallic capillary connexions $(\S \vec{b})$ between bulb and manometer with impunity; that the platinum-iridium (20 per cent.) thermocouple is free from serious anomalies; that in using the furnace and the reentrant bulb, a virtual identity of environment for the thermocouple and the airthermometer had actually been secured; and that, finally, the methods preliminarily tested in the above pages are sufficient for the rigorous solution of the calibration problem up to an accuracy of $1^{\circ}$ in $1000^{\circ}$.

18. Conclusion.-For some years I have had the parts of a standard constant-pressure high-temperature air-thermometer in the laboratory, but have been prevented, by duties of a more immediate geological bearing, from putting them together. I will briefly refer to these parts here.

In the manometer, volumes are to be read to 05 cub. $\mathrm{cm}$., temperatures to $\cdot 07^{\circ} \mathrm{C}$., and pressures to $01 \mathrm{~cm}$. of mercury. Hence I surround both branches of the U-tube with a tubular cistern, through which water at constant temperature continually circulates. Moreover, both branches are now made of glass and communicate below, by means of a suitable stopcock, with an external flexible tube surmounted by a mercury reservoir, by which pressure may be changed at pleasure. A sufficient length of the metallic capillary between bulb and manometer is also submerged in the water, so that the fine current of air within may enter the manometer, already reduced to the temperature of the bath. Finally, instead of employing a cylindrical volume-tube in the manometer, as was done above, whereby the accuracy of measurement becomes rapidly insufficient in proportion as the air-thermometer temperature rises (see distribution of points on the chart, Pl. I.), the first $100 \mathrm{cub}$. cm. of the tube are blown out into a spherical bulb, and the remaining length of $140 \mathrm{~cm}$. of the tube utilized to measure the remaining $150 \mathrm{cub}$. $\mathrm{cm}$. Thus even $01 \mathrm{cub} . \mathrm{cm}$. is appreciable, and the tube is now available for accurate measurements between about $200^{\circ}$ and over $1500^{\circ}$.

Again, since the normal volume of the gas actually expanding must be known to $.01 \mathrm{cub}$. cm., it is necessary to reduce the stem volume of variable temperature to the smallest limits Phil. Mag. s o. Vol. 34. No. 206. July 1892. 
Phi. Mas. S. 5 Wol 4 . P.I.

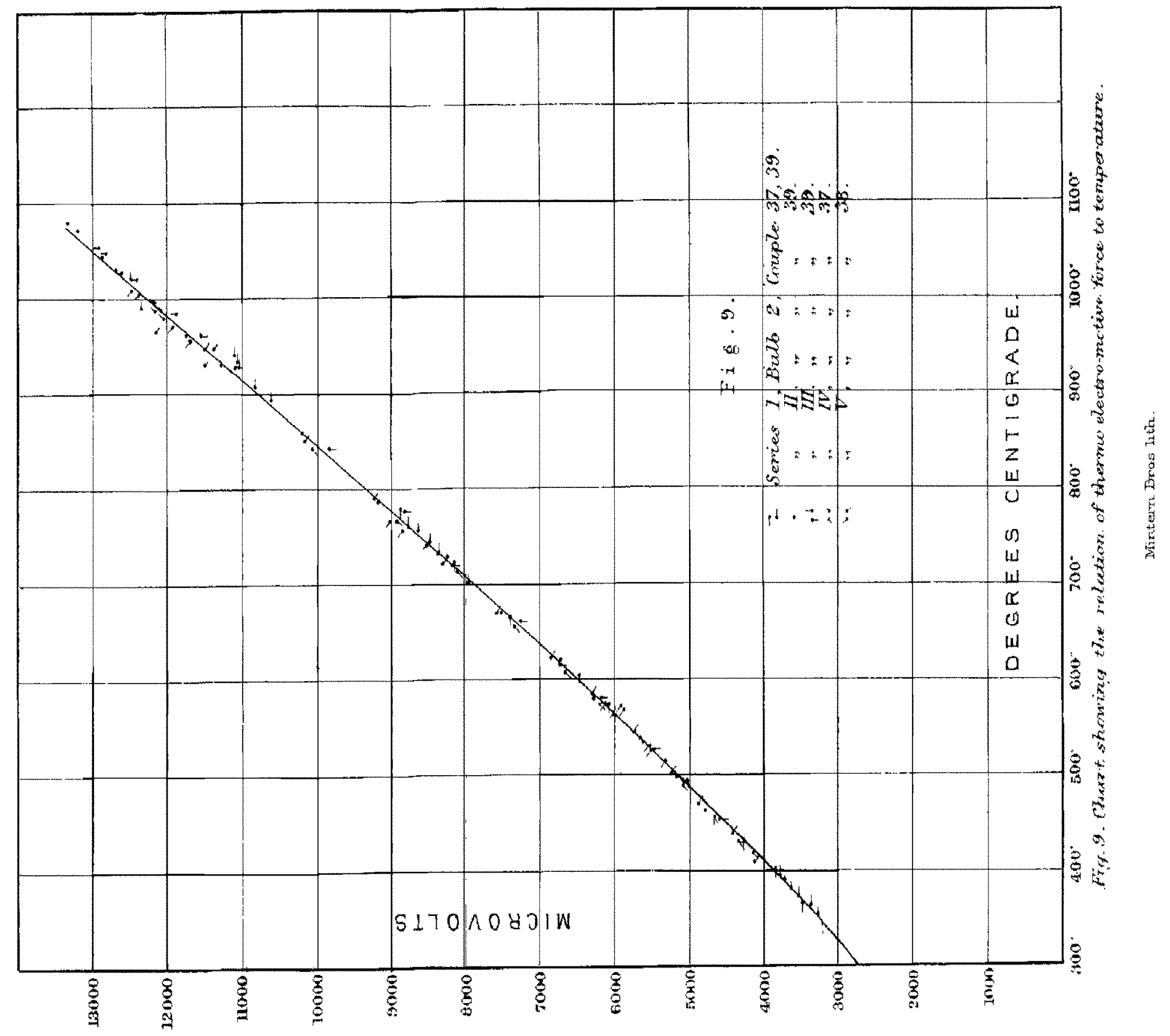


possible. To accomplish this, a platinum capillary tube is to be cemented into the stem of the porcelain air-thermometer, by bringing atmospheric pressure to bear on the outside of the exhausted bulb, while the neck is being heated on the revolving table by the oxyhydrogen blowpipe, to the point of sufficiently reduced viscosity for adhesion. Experiment must show whether the bulb of the type figure 2 will ultimately answer all requirements, or whether a bulb which combines the features of figs. 2 and 3 will be necessary. Note that an independent method of standardization of the non-inglazed reentrant porcelain air-thermometer bulb, by thermal comparison with a reentrant glass air-thermometer bulb, of known constants, is also feasible. Such a comparison is to be made above $200^{\circ}$, to obviate all moisture and condensation errors, and either directly, in the elliptical revolving muffle $(\$ 9)$, or indirectly, through the intervention of the same thermocouple. I have constructed vapour baths (naphthalene, diphenylamine) for this purpose.

I may add, in passing, that during my experiments with molten rock I was surprised by the tenacity with which the basic magma adheres to platinum and protects it. A platinum bulb covered with some refractory glazing may therefore be looked to, when temperatures beyond the reach of the porcelain bulb (say about $1400^{\circ}$ ) are to be measured. I believe, however, that for the case of platinum apparatus, the method of absolute air-thermometry based on the high temperature viscosity of gases is more promising, if only some mathematical physicist would give us an expression for the dependence of gaseous viscosity on temperature. It seems strange that this important relation has thus far eluded search, and that little is known beyond the ingenious surmises of $O$. E. Meyer and the empiric law of my own. Inasmuch as the time of transpiration varies nearly as the $5 / 3$ power of absolute temperature, the sensitiveness of the method is obvious.

Phys. Lab., U. S. G.S.,

Washington, D.C.

II. The "Elastic Medium" Method of treating Electrostatic Theorems. By W. H. Bragg, M.A., Professor of Mathematics in the University of Adelaide, South Australia*.

T $T$ is usual to deduce the ordinary theorems of electro1 statics from the law that two amounts of electricity repel one another with a force proportional directly to the product of these amounts and inversely to the square of the distance

* Communicated by the Author. 